Check for updates

Cite this: RSC Adv., 2019, 9, 13082

Received 21st February 2019

Accepted 23rd April 2019

DOI: 10.1039/c9ra01327j

rsc.li/rsc-advances

\section{Three new metal coordination polymers of bifunctional imidazolate/tetrazolate bridges: the only example of a three-dimensional framework based on rare $\left[\mathrm{CO}_{4}\left(\mu_{3}-\mathrm{OH}\right)_{2}\left(\mu_{2}-\mathrm{Cl}\right)_{2}\right]^{4+}$ mixed oxo- chloro-clusters $\dagger$}

\begin{abstract}
Lili Yang, ${ }^{a}$ Jian Zhou, (D) *a Hua-Hong Zou (DD *b and Qiuling Tanga
Three new metal coordination polymers $\left[\mathrm{Ni}\left(\mu_{2}-\mathrm{L}\right)_{2}\left(\mathrm{H}_{2} \mathrm{O}\right)_{2}\right]_{n}(1, \mathrm{HL}=1$-tetrazole-4-imidazole-benzene), $\left[\mathrm{Co}\left(\mu_{2}-\mathrm{L}\right)_{2}\right]_{n}(2)$, and $\left[\mathrm{CO}_{4}\left(\mu_{3}-\mathrm{OH}\right)_{2}\left(\mu_{2}-\mathrm{Cl}\right)_{2}\left(\mu_{5}-\mathrm{L}\right)_{2}\left(\mu_{2}-\mathrm{L}\right)_{2}\right]_{n} \cdot 7 n \mathrm{H}_{2} \mathrm{O}(3)$ were hydrothermally synthesized and structurally characterized. 1 displays a neutral $\left[\mathrm{Ni}\left(\mu_{2}-\mathrm{L}\right)_{2}\left(\mathrm{H}_{2} \mathrm{O}\right)_{2}\right]_{n}$ chain built up from the $\mathrm{Ni}^{2+}$ ions bridged by deprotonated $\mathrm{L}^{-}$ligands, while 2 shows another rare neutral $\left[\mathrm{Co}\left(\mu_{2}-\mathrm{L}\right)_{2}\right]_{n}$ chain based on $\mathrm{Co}^{2+}$ ions connected by two different coordination modes of the $L^{-}$ligand. 3 exhibits a rare $\left[\mathrm{CO}_{4}\left(\mu_{3}-\mathrm{OH}\right)_{2}\left(\mu_{2^{-}}\right.\right.$ $\left.\mathrm{Cl}_{2}\right]^{4+}$ mixed oxo-chloro-cluster-based three-dimensional framework with large elliptical channels, which are filled by unprecedented chilopod $\left[\left(\mathrm{H}_{2} \mathrm{O}\right)_{7}\right]_{n}$ chains. Both 1 and 2 show antiferromagnetic behavior, while 3 exhibits unusual spin-canting.
\end{abstract}

\section{Introduction}

Magnetic metal coordination polymers with varied fascinating architectures associated with rich magnetic character have attracted considerable attention, due to their potential applications in high-density information storage and processing, quantum computing, and molecular spintronics devices. ${ }^{1}$ The appropriate bridging ligands between paramagnetic metal ions have a significant effect on the magnetic behaviors via transmitting magnetic coupling efficiently. Five-membered heterocyclic polyazoles (such as imidazole,$^{2}$ triazole $^{3}$ and tetrazole ${ }^{4}$ ) and their derivatives are excellent candidates for active magnetic bridges, because their various bridging modes can aggregate multiple metal ions into polynuclear clusters and engage in superexchange interactions to offer materials with useful magnetic properties. Among these polyazoles, imidazolates can be efficient heterocyclic bridging ligands for the syntheses of molecule-based magnets, due to the absence of an inversion center along the NCN bridge, ${ }^{2}$ while tetrazoles with

${ }^{a}$ Chongqing Key Laboratory of Inorganic Functional Materials, College of Chemistry, Chongqing Normal University, Chongqing 401331, P. R. China. E-mail: Jianzhou888888@163.com

${ }^{b}$ State Key Laboratory for Chemistry and Molecular Engineering of Medicinal Resources, School of Chemistry \& Pharmacy of Guangxi Normal University, Guilin 541004, P. R. China. E-mail: gxnuchem@foxmail.com

$\dagger$ Electronic supplementary information (ESI) available: Crystal data in CIF format, XRD data, the magnetization versus the dc field in the temperature range of 2-5 K for 3, and some figures. CCDC 1892465 (1), 1892466 (2) and 1865774 (3). For ESI and crystallographic data in CIF or other electronic format see DOI: $10.1039 / \mathrm{c} 9 \mathrm{ra} 01327 \mathrm{j}$ antisymmetric bridging modes can produce antisymmetric superexchange interactions, resulting in spin canting behavior and long-range magnetic ordering. ${ }^{4}$ Expectedly, the coexistence of imidazole and tetrazole in the same organic framework may generate a new class of bifunctional bridging ligands. The representative bifunctional bridge is 1-tetrazole-4-imidazolebenzene (HL) containing one imidazole and one tetrazole, which was used mainly for the construction of luminescent coordination polymers of $\mathrm{d}^{\mathbf{1 0}}$ metal ions (such as $\mathrm{Cu}^{+}, \mathrm{Ag}^{+}, \mathrm{Zn}^{2+}$ and $\mathrm{Cd}^{2+}$ ) owing to its aromatic chromophore and diverse bridging modes. ${ }^{5}$ However, its magnetic coordination polymers of paramagnetic metal ions (such as $\mathrm{Mn}^{2 / 3+}, \mathrm{Fe}^{2 / 3+}, \mathrm{Co}^{2+}$, and $\mathrm{Ni}^{2+}$ ) have been less explored, and the limited examples are cobalt(II) coordination polymers $\left[\mathrm{Co}_{2}(\mathrm{~L})_{2}(\mathrm{HL})\left(\mathrm{H}_{2} \mathrm{O}\right)_{2}\right][(\beta-$ $\left.\left.\mathrm{Mo}_{8} \mathrm{O}_{26}\right)_{0.5}\right]^{6 a}$ and $\left[\mathrm{Co}_{2}(\mathrm{~L})_{2}(\mathrm{pbda})-\left(\mathrm{H}_{2} \mathrm{O}\right)_{3}\right] \quad\left(\mathrm{H}_{2} \mathrm{pbda}=1,4-\right.$ benzene-dicarboxylic acid), ${ }^{6 b}$ which all show antiferromagnetic behavior, but other important magnetic behaviors have not been documented.

Moreover, the bifunctional bridged ligands containing imidazole and tetrazole groups coordinate to the iron group metal ions to usually generate a variety of metal coordination polymers with octahedrally coordinated metal centers, ${ }^{5,6}$ but their magnetic metal coordination polymers with tetrahedrally coordinated metal centers have not been to date documented, because of synthetic difficulties. The low coordination number of the metal complexes with tetrahedrally coordinated metal centers splitting the d orbitals with a small separation is preferable to form a weak ligand field, which might facilitate the spin-orbital coupling to enhance the magnetic anisotropy, thus resulting in slow magnetic relaxation. ${ }^{7}$ It is expected that the 
combination of the magnetic metal ions with tetrahedrally coordinated metal centers and the bifunctional imidazole/ tetrazole bridges in the same coordination polymeric frameworks may give a new class of coordination polymers with novel structures and useful magnetic properties. With regard to all aspects stated above, we chose HL as magnetic active bridge, and $\mathrm{Co}^{2+} / \mathrm{Ni}^{2+}$ ions as the paramagnetic centre based on the listed below considerations: (a) HL containing two types of heterocyclic polyazoles can not only act as a various magnetic bridges to offer varied architectures and superexchange capacity that might produce significant magnetic properties, but also serve as a diamagnetic separator, owing to tetrazole and imidazole rings separated by benzene ring. (b) $\mathrm{Co}^{2+}$ and $\mathrm{Ni}^{2+}$ ions are selected as the paramagnetic metal ions that could result in unusual magnetic behaviors. ${ }^{4,8}$ As a result, three new coordination polymers $\left[\mathrm{Ni}\left(\mu_{2}-\mathrm{L}\right)_{2}\left(\mathrm{H}_{2} \mathrm{O}\right)_{2}\right]_{n}(\mathbf{1}),\left[\mathrm{Co}\left(\mu_{2}-\mathrm{L}\right)_{2}\right]_{n}$ (2), $\left[\mathrm{Co}_{4}\left(\mu_{3}-\mathrm{OH}\right)_{2}\left(\mu_{2}-\mathrm{Cl}\right)_{2}\left(\mu_{5}-\mathrm{L}\right)_{2}\left(\mu_{2}-\mathrm{L}\right)_{2}\right]_{n} \cdot 7 n \mathrm{H}_{2} \mathrm{O}(3)$ were obtained by hydrothermal methods. 1 shows the $\left[\mathrm{Ni}\left(\mu_{2}-\mathrm{L}\right)_{2}\left(\mathrm{H}_{2} \mathrm{O}\right)_{2}\right]_{n}$ chain with six-coordinate $\mathrm{Ni}^{2+}$ center, while 2 exhibits another rare $\left[\mathrm{Co}\left(\mu_{2}-\mathrm{L}\right)_{2}\right]_{n}$ chain based on four-coordinate $\mathrm{Co}^{2+}$ centres. 3 offers the only example of three-dimensional framework incorporating rare mixed oxo-chloro-clusters $\left[\mathrm{Co}_{4}\left(\mu_{3}-\mathrm{OH}\right)_{2}\left(\mu_{2}\right.\right.$ $\left.\mathrm{Cl})_{2}\right]^{4+}$, mainly because the reported magnetic $\left[\mathrm{M}_{x} \mathrm{Q}_{y}\right](\mathrm{Q}=-\mathrm{OH}$ or halogen element) clusters bonding directly to either tetrazole or its derivatives contain only one type of bridge, such as $\left[\mathrm{Cu}_{3}\left(\mu_{3}-\mathrm{OH}\right)\right]^{5+}(\mathrm{M}=\mathrm{Mn}, \mathrm{Co}, \mathrm{Cu}){ }^{9}\left[\mathrm{M}_{4}\left(\mu_{3}-\mathrm{OH}\right)_{2}\right]^{6+}(\mathrm{M}=\mathrm{Mn}$, $\mathrm{Co}){ }^{10}\left[\mathrm{Co}_{4}\left(\mu_{3}-\mathrm{Cl}\right)\right]^{7+},{ }^{11}$ and $\left[\mathrm{Co}_{5}\left(\mu_{3}-\mathrm{F}\right)_{2}\right]^{8+},{ }^{10 a}$ but the coexistence of $-\mathrm{OH}$ and halogen bridges in the same magnetic clusters is only observed in $\left[\mathrm{Co}_{4}\left(\mu_{3}-\mathrm{OH}\right)_{2}\left(\mu_{2}-\mathrm{Cl}\right)_{2}\right]^{4+}$ cluster of 3 .

\section{Experimental}

\section{General remarks}

All reagents in the preparation procedure were of analytical reagent grade and used without any purification or degassing of solvents. Elemental analyses $(\mathrm{C}$ and $\mathrm{H})$ were performed using a PE2400 II elemental analyzer. FT-IR spectra were recorded with a Nicolet Magna-IR 550 spectrometer in dry KBr disks in the $4000-400 \mathrm{~cm}^{-1}$ range. The solid-state UV/Vis spectra were measured at room temperature using a PE Lambda $900 \mathrm{UV} / \mathrm{Vis}$ spectrophotometer. Powder X-ray diffraction (XRD) patterns were recorded in the angular range of $2 \theta=5-60^{\circ}$ on a Bruker D8 advance diffractometer using $\mathrm{CuK} \alpha$ radiation. All magnetization of compounds 1-3 were obtained with a Quantum Design MPMS-XL-5 magnetometer.

Synthesis of $\left[\mathrm{Ni}\left(\mu_{2}-\mathbf{L}\right)_{2}\left(\mathrm{H}_{2} \mathrm{O}\right)_{2}\right]_{\boldsymbol{n}}(\mathbf{1})$. The reactants of $\mathrm{H}_{3} \mathrm{BO}_{3}$ (0.1014 g, $1.6 \mathrm{mmol}), \mathrm{NiCl}_{2}(0.0899 \mathrm{~g}, 0.7 \mathrm{mmol}), \mathrm{HL}$ (0.0256 g, $0.12 \mathrm{mmol}$ ) was stirred for $0.5 \mathrm{~h}$, and then the final mixture was sealed in a $25 \mathrm{~mL}$ Teflon lined autoclave. The reaction was heated at $170{ }^{\circ} \mathrm{C}$ for 7 days. After cooling to room temperature slowly, orange sheet crystals of 1 in about 51\% (based on HL) were obtained. Anal calc. (found \%) for $\mathrm{C}_{20} \mathrm{H}_{18} \mathrm{~N}_{12} \mathrm{NiO}_{2}$ (1): C 46.45 (46.53), H 3.51 (3.59), N 32.50 (32.61). IR ( $\left.\mathrm{KBr}, \mathrm{cm}^{-1}\right)$ : 3420(m), 3096(m), 1543(m), 1515(s), 1440(m), 1311(m), 1255(m), 1117(w), 1079(m), 960(m), 849(s), 747(m), 655(m), $535(\mathrm{~m})$.
Synthesis of $\left[\mathrm{Co}\left(\mu_{2}-\mathrm{L}\right)_{2}\right]_{n}$ (2). The reactants of $\mathrm{H}_{3} \mathrm{BO}_{3}$ $(0.1082 \mathrm{~g}, 1.7 \mathrm{mmol}), \mathrm{CoCl}_{2}(0.0313 \mathrm{~g}, 0.24 \mathrm{mmol}), \mathrm{HL}(0.0253 \mathrm{~g}$, $0.12 \mathrm{mmol})$ and $\mathrm{H}_{2} \mathrm{O}(2.0 \mathrm{~mL})$ was stirred for $0.5 \mathrm{~h}$, and then the final mixture was sealed in a $25 \mathrm{~mL}$ Teflon lined autoclave. The reaction was heated at $170{ }^{\circ} \mathrm{C}$ for 7 days. After cooling to room temperature slowly, purple block crystals of 2 in about $43 \%$ (based on $\mathrm{HL}$ ) were obtained. Anal calc. (found \%) for $\mathrm{C}_{20} \mathrm{H}_{14} \mathrm{CoN}_{12}$ (1): C 49.91 (49.96), H 2.93 (2.98), N 34.92 (34.97). IR $\left(\mathrm{KBr}, \mathrm{cm}^{-1}\right): 3135(\mathrm{~s}), 1612(\mathrm{~m}), 1546(\mathrm{~m}), 1511(\mathrm{~s}), 1443(\mathrm{~s})$, 1368(m), 1309(s), 1105(m), 1065(s), 954(m), 845(s), 758(m), 649(s), 534(m).

Synthesis of $\left[\mathrm{Co}_{4}\left(\mu_{3}-\mathrm{OH}\right)_{2}\left(\mu_{2}-\mathrm{Cl}\right)_{2}\left(\mu_{5}-\mathrm{L}\right)_{2}\left(\mu_{2}-\mathrm{L}\right)_{2}\right]_{n} \cdot 7 n \mathrm{H}_{2} \mathrm{O}(3)$. The reactants of $\mathrm{H}_{3} \mathrm{BO}_{3}(0.1093 \mathrm{~g}, 1.8 \mathrm{mmol}), \mathrm{CoCl}_{2}(0.0651 \mathrm{~g}$, $0.5 \mathrm{mmol}), \mathrm{HL}(0.0266 \mathrm{~g}, 0.13 \mathrm{mmol})$ and $\mathrm{H}_{2} \mathrm{O}(2.0 \mathrm{~mL})$ was stirred for $0.5 \mathrm{~h}$, and then the final mixture was sealed in a $25 \mathrm{~mL}$ Teflon lined autoclave. The reaction was heated at $170{ }^{\circ} \mathrm{C}$ for 7 days. After cooling to room temperature slowly, red needle-like crystals of 3 in about $63 \%$ (based on $\mathrm{HL}$ ) were obtained. Anal calc. (found \%) for $\mathrm{C}_{40} \mathrm{H}_{44} \mathrm{Cl}_{2} \mathrm{Co}_{4} \mathrm{~N}_{24} \mathrm{O}_{9}$ (3): C 36.63 (36.70), H 3.38 (3.43), N 25.63 (25.71). IR ( $\left.\mathrm{KBr}, \mathrm{cm}^{-1}\right): 3619(\mathrm{~m})$, 3453(m), 3131(s), 1608(s), 1499(vs), 1442(vs), 1363(m), 1284(vs), 1128(w), 1060(s), 825(s), 746(m), 650(m), 561(w), 484(w).

\section{X-ray crystallography}

Diffraction intensity data for 1-3 were recorded on a Rigaku Mercury CCD diffractometer using a $\omega$-scan method with graphite monochromated Mo $\mathrm{K} \alpha$ radiation $(\lambda=0.71073 \AA)$. Absorption corrections were applied using multi-scan technique. The structures of 1-3 were solved by direct methods (SHELXS-97) ${ }^{\mathbf{1 2}}$ and refined by full-matrix least-squares techniques using the SHELXL-97 program. ${ }^{13}$ All non-H atoms were refined anisotropically. The $\mathrm{H}$ atoms of $\mathrm{L}^{-1}$ ligands were added geometrically and refined as riding on their parent atoms with fixed isotropic displacement parameters. Relevant crystal collection data parameters and refinement results can be found in Table 1. CCDC numbers are 1892465 (1), 1892466 (2) and 1865774 (3).

\section{Results and discussion}

\section{Synthetic aspects}

The crystals of 1-3 were obtained by the reaction of $\mathrm{MCl}_{2}(\mathrm{M}=$ $\mathrm{Co}, \mathrm{Ni}), \mathrm{H}_{3} \mathrm{BO}_{3}$ and $\mathrm{HL}$ in water solution at $170{ }^{\circ} \mathrm{C}$. Although $\mathrm{H}_{3} \mathrm{BO}_{3}$ is not introduced into the final structure, numerous paralleling experiments affirmed that 1-3 cannot be obtained in the absence of $\mathrm{H}_{3} \mathrm{BO}_{3}$, showing that the $\mathrm{H}_{3} \mathrm{BO}_{3}$ may take a role as structural directing agent. The parallel experiments reveal that the reactant stoichiometry and initial reactants can influence the outcome of reaction. For instance, when the quantity of $\mathrm{CoCl}_{2}$ was increased to two times under the similar synthetic procedure to 2 , red crystals of 3 containing mixed oxo-chloroclusters $\left[\mathrm{Co}_{4}\left(\mu_{3}-\mathrm{OH}\right)_{2}\left(\mu_{2}-\mathrm{Cl}\right)_{2}\right]^{4+}$ were isolated. With the aim of preparing an analogue of 3 , we tried to replace $\mathrm{CoCl}_{2}$ with $\mathrm{NiCl}_{2}$ alone, but these attempts failed and orange crystal of $\mathbf{1}$ was the only pure product isolated. The IR spectra of $\mathbf{1}$ and $\mathbf{3}$ show the several strong absorptions in the range of $3420-3619 \mathrm{~cm}^{-1}$, 
indicative of the characteristic $v_{-\mathrm{OH}}$ vibration of $-\mathrm{OH}$ groups and $\mathrm{H}_{2} \mathrm{O}$ molecules, but no similar $v_{-\mathrm{OH}}$ vibration is observed in 2. The peak at $3131 \mathrm{~cm}^{-1}$ can be assigned to $v_{\mathrm{C}-\mathrm{H}}$ stretching, while the several bands in the range of $1284-1612 \mathrm{~cm}^{-1}$ are attributed to the characteristic $v_{\mathrm{C}-\mathrm{N}}, v_{\mathrm{C}=\mathrm{C}}$ and $v_{\mathrm{N}=\mathrm{N}}$ vibrations of the $\mathrm{L}^{-}$ligand. The phase purities of 1-3 are confirmed by PXRD analysis (Fig. S1†).

\section{Description of the structure}

Description of $\left[\mathrm{Ni}\left(\mu_{2}-\mathrm{L}\right)_{2}\left(\mathrm{H}_{2} \mathrm{O}\right)_{2}\right]_{n}(1)$ and $\left[\mathrm{Co}\left(\mu_{2}-\mathrm{L}\right)_{2}\right]_{n}(2) .1$ crystallizes in triclinic space group $P \overline{1}$ and its asymmetric unit contains one unique $\mathrm{L}^{-}$ligand, one coordinated $\mathrm{H}_{2} \mathrm{O}$, and half of a $\mathrm{Ni}^{2+}$ ion located at the special position with 2-fold symmetry (Fig. S2a $\uparrow$ ). The $\mathrm{Ni}^{2+}$ ion is octahedrally coordinated to four $\mathrm{N}$ atoms from four $\mathrm{L}^{-}$ligands and two $\mathrm{H}_{2} \mathrm{O}$ molecules. The Ni-O and $\mathrm{Ni}-\mathrm{N}$ bond lengths are normal and call for no further comment. ${ }^{14}$ The neighboring complex $\left[\mathrm{Ni}\left(\mathrm{H}_{2} \mathrm{O}\right)_{2}\right]^{2+}$ cations are bridged by double $\mathrm{L}^{-}$ligands to give a chain $\left[\mathrm{Ni}\left(\mu_{2}-\mathrm{L}\right)_{2}\left(\mathrm{H}_{2} \mathrm{O}\right)_{2}\right]_{n}$ (Fig. 1a) with a $\mathrm{Ni} \cdots \mathrm{Ni}$ distance of $10.98 \AA$.

2 crystallizes in monoclinic space group $C 2 / c$. The asymmetric unit contains one unique $\mathrm{Co}^{2+}$ ions and two $\mathrm{L}^{-}$ligands (Fig. S2b $\dagger$ ). Each $\mathrm{Co}^{2+}$ ion adopts a tetrahedral coordination mode comprised of four $\mathrm{N}$ atoms from four $\mathrm{L}^{-}$ligands. The Co$\mathrm{N}$ bond lengths are in the range of 1.995(3)-2.018(3) $\AA$, comparable to corresponding values (1.855(5)-2.155(4) $\AA$ ) in other compounds. ${ }^{7 c}$ The $\mathrm{L}^{-}$ligand shows two different bridging modes, namely, $\mu_{2}-\kappa \mathrm{N} 1: \kappa \mathrm{N} 3$ and $\mu_{2}-\kappa \mathrm{N} 7: \kappa \mathrm{N} 12$. The neighboring $\mathrm{Co}^{2+}$ ions are bridged by $\mu_{2}-\kappa \mathrm{N} 1: \kappa \mathrm{N} 3$ bridging ligand to form a $\left[\mathrm{Co}_{2} \mathrm{~L}_{2}\right]$ dimer with a $\mathrm{Co} \cdots$ Co distance of $10.54 \AA$. The $\left[\mathrm{Co}_{2} \mathrm{~L}_{2}\right]$ dimer units are interconnected via $\mu_{2}-\kappa N 7: \kappa N 12$ bridging ligand to form a chain $\left[\mathrm{Co}\left(\mu_{2}-\mathrm{L}\right)_{2}\right]_{n}$ with elliptical ring (Fig. 1b).

Description of $\left[\mathrm{Co}_{4}\left(\mu_{3}-\mathrm{OH}\right)_{2}\left(\mu_{2}-\mathrm{Cl}\right)_{2}\left(\mu_{5}-\mathrm{L}\right)_{2}\left(\mu_{2}-\mathrm{L}\right)_{2}\right]_{n} \cdot 7 n \mathrm{H}_{2} \mathrm{O}$ (3). 3 crystallizes in monoclinic space group $\mathrm{C} 2 / \mathrm{c}$ and its asymmetric unit contains two $\mathrm{Co}^{2+}$ ions, two $\mathrm{L}^{-}$ligands, one $\mathrm{Cl}^{-}$ anion, one - $\mathrm{OH}$ group, three and half of $\mathrm{H}_{2} \mathrm{O}$, where $\mathrm{O} 3 \mathrm{~W}$ atom is seated at the special position with 2-fold symmetry (Fig. 2a).

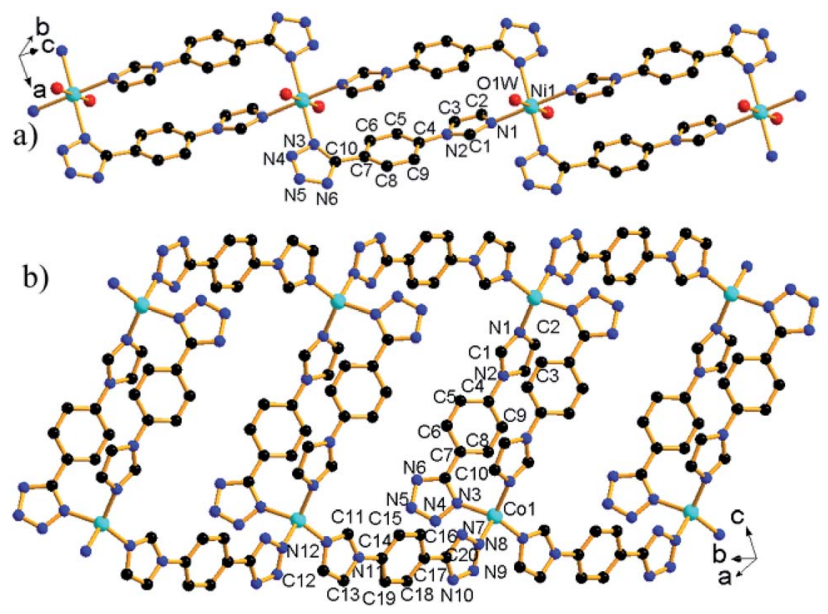

Fig. 1 The structures of $\left[\mathrm{Ni}\left(\mu_{2}-\mathrm{L}\right)_{2}\left(\mathrm{H}_{2} \mathrm{O}\right)_{2}\right]_{n}$ (a) and $\left[\mathrm{Co}\left(\mu_{2}-\mathrm{L}\right)_{2}\right]_{n}$ (b) chains. All $\mathrm{H}$ atoms bonded to $\mathrm{C}$ and $\mathrm{O}$ atoms have been omitted for clarity.

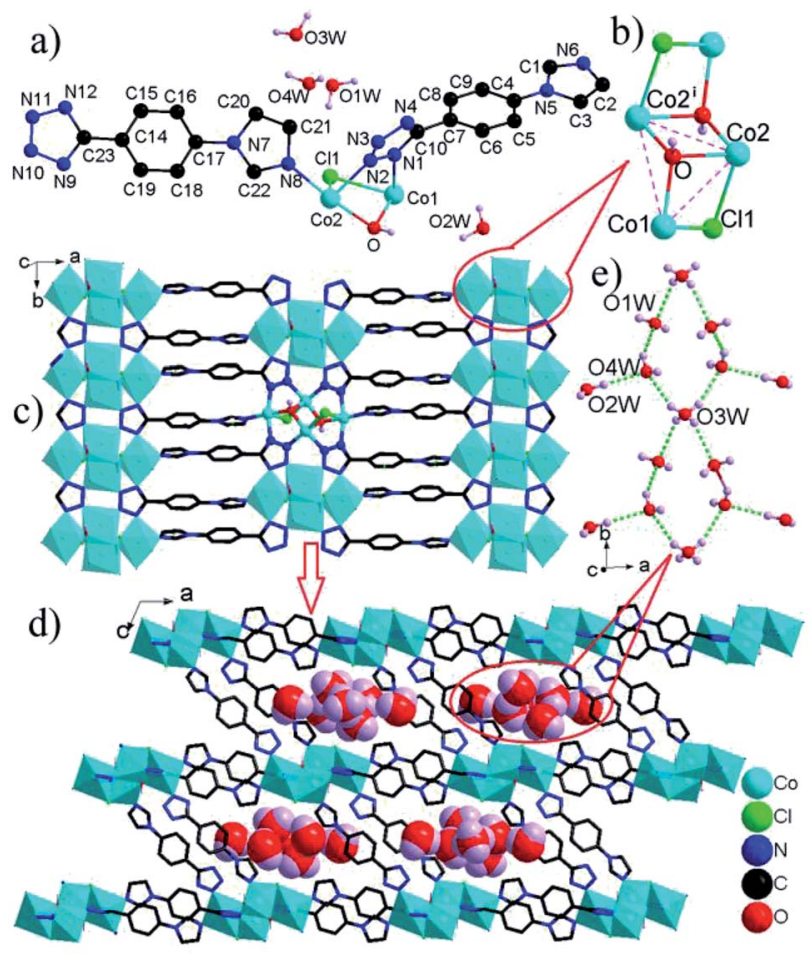

Fig. 2 (a) The asymmetric unit of 3 with labeling scheme. (b) $\left[\mathrm{CO}_{4}\left(\mu_{3}-\right.\right.$ $\mathrm{OH})_{2}\left(\mu_{2}-\mathrm{Cl}_{2}\right]^{4+}$ mixed oxo-chloro-cluster [symmetry operation: (i) $-x$, $-y, 1-z]$. (c) The layer built from $\left[\mathrm{CO}_{4}\left(\mu_{3}-\mathrm{OH}\right)_{2}\left(\mu_{2}-\mathrm{Cl}\right)_{2}\right]^{4+}$ clusters and L1 ligands. (d) Three-dimensional framework of 3. (e) chilopod $\left[\left(\mathrm{H}_{2} \mathrm{O}\right)_{7}\right]_{n}$ chain. $\mathrm{H}$ atoms bonded to $\mathrm{C}$ atoms are omitted for clarity.

$\operatorname{Co}(1)^{2+}$ ion adopts an octahedral coordination environment comprised of four $\mathrm{N}$ atoms from four different $\mathrm{L}^{-}$ligands, one $\mu_{2}-\mathrm{Cl}^{-}$ion and one $\mu_{3}-\mathrm{OH}$ group, while $\mathrm{Co}(2)^{2+}$ ion has a similar octahedron ligated by three $\mathrm{N}$ atoms from three different $\mathrm{L}^{-}$ ligands, one $\mu_{2}-\mathrm{Cl}^{-}$ion and two $\mu_{3}-\mathrm{OH}$ groups. The Co-N/O bond lengths are in the range of 2.056(3)-2.206(4) $\AA$, and the Co-Cl bond lengths vary from 2.5232(12) to 2.5251(12) $\AA$, which are compared with corresponding bond lengths (2.032(2)2.206(2) $\mathrm{A}$ for $\mathrm{Co}-\mathrm{N} / \mathrm{O}$ and 2.428(1)-2.7019(7) $\AA$ for $\mathrm{Co}-\mathrm{Cl})$ in

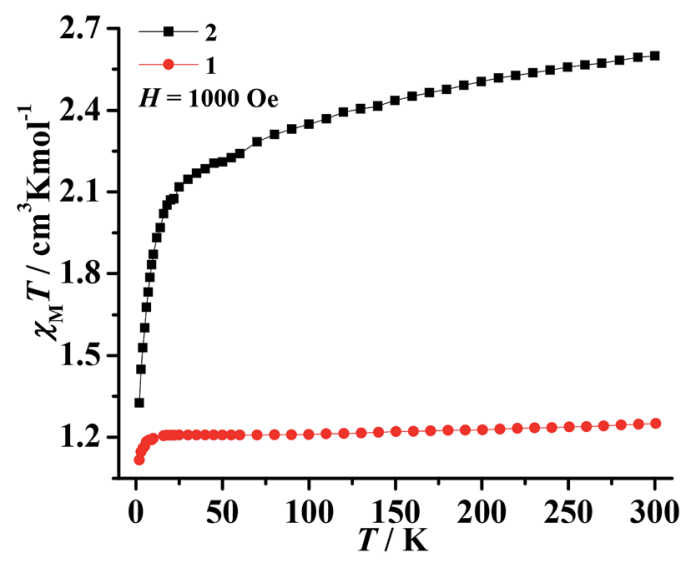

Fig. 3 Temperature dependence of the $\chi_{M} T$ product for $1-2$ at 1000 Oe. 

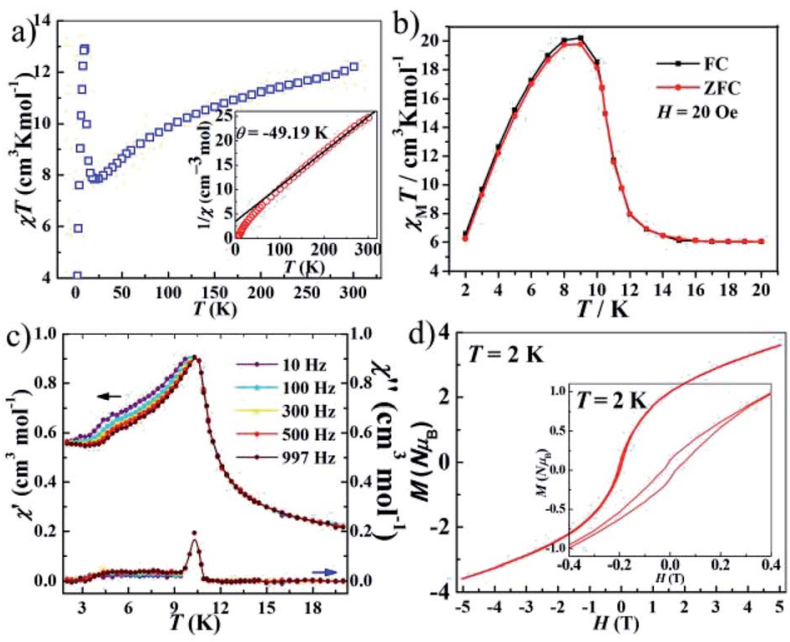

Fig. 4 (a) The temperature dependence of $\chi_{\mathrm{m}} T$ under $H_{\mathrm{dc}}=1000 \mathrm{Oe}$ between 2 and $300 \mathrm{~K}$ (inset: fitting $C$ and $\theta$ of $1 / \chi$ for 3 ). (b) ZFC and FC curves at 20 Oe. (c) The temperature dependence of the in-phase $\left(\chi^{\prime}\right)$ and out-of-phase $\left(\chi^{\prime \prime}\right)$ ac-susceptibilities for different frequencies in zero dc-field for 3 . (d) The isothermal field dependence of magnetization at $2 \mathrm{~K}$.

other compounds. ${ }^{11,15}$ There are two bridging modes of $\mathrm{L}^{-}$ ligand (denoted as L1 and L2, Fig. S3 $\dagger$ ) in 3. The L1 ligand shows a $\mu_{5}-\kappa \mathrm{N} 1: \kappa \mathrm{N} 2: \kappa \mathrm{N} 3: \kappa \mathrm{N} 4: \kappa \mathrm{N} 6$ bridging mode, while the L2 ligand exhibits a $\mu_{2}-\kappa N 8: \kappa N 11$ bridging mode. All atoms in L1 and L2 are not coplanar, mainly because the dihedral angle of benzene ring and imidazole ring is $8.19^{\circ}$ for $\mathrm{L} 1$ and $26.54^{\circ}$ for $\mathrm{L} 2$, and the dihedral angle of benzene ring and tetrazole ring is $65.31^{\circ}$ for L1 and $8.29^{\circ}$ for L2. Four $\mathrm{Co}^{2+}$ ions are bridged by two $\mu_{3}-\mathrm{OH}$ groups and two $\mu_{2}-\mathrm{Cl}^{-}$ions to form a novel tetra-nuclear
$\left[\mathrm{Co}_{4}\left(\mu_{3}-\mathrm{OH}\right)_{2}\left(\mu_{2}-\mathrm{Cl}\right)_{2}\right]^{4+}$ mixed oxo-chloro-cluster with Co $\cdots \mathrm{Co}$ distances of 3.127-3.596 ̊ (Fig. 2b). This cluster might be also viewed as a derivative of the butterfly-shaped $\left[\mathrm{Co}_{4}\left(\mu_{3}-\mathrm{OH}\right)_{2}\right]$ cluster, whose $\mathrm{Co}^{2+}$ ions are further bridged by two $\mu_{2}-\mathrm{Cl}^{-}$ions.

The $\left[\mathrm{Co}_{4}\left(\mu_{3}-\mathrm{OH}\right)_{2}\left(\mu_{2}-\mathrm{Cl}\right)_{2}\right]^{4+}$ clusters are interconnected by $\mathrm{L} 1$ ligands to form an infinite $\left[\mathrm{Co}_{4}\left(\mu_{3}-\mathrm{OH}\right)_{2}\left(\mu_{2}-\mathrm{Cl}\right)_{2}\right]^{4+}$ cluster-based 2-D layer (Fig. 2c). The nearest Co $\cdots$ Co distance between adjacent clusters spanned by tetrazole ring of $\mathrm{L}^{-}$ligand is much shorter than that by whole $\mathrm{L}^{-}$connector (4.21 versus $10.43 \AA$ ), resulting in the significant superexchange interactions within the Co-tetrazole ribbon. These layers are further bridged by $\mathrm{L} 2$ ligands to generate a three-dimensional network structure with large elliptical channels filled by $\left[\left(\mathrm{H}_{2} \mathrm{O}\right)_{7}\right]_{n}$ chilopod chains (Fig. 2d). The free $\mathrm{H}_{2} \mathrm{O}$ molecules are interconnected via $\mathrm{O}-\mathrm{H} \cdots \mathrm{O}$ H-bonds to form chilopod $\left[\left(\mathrm{H}_{2} \mathrm{O}\right)_{7}\right]_{n}$ chain (Fig. 2e), which contains cyclic hexamer $\left(\mathrm{H}_{2} \mathrm{O}\right)_{6}$ with a pseudo-crown conformation (Fig. $\mathrm{S} 4 \dagger$ ) and $\mathrm{H}_{2} \mathrm{O}(2 \mathrm{~W})$ foot. The average $\mathrm{O} \cdots \mathrm{O}$ distance of $2.894 \AA$ is close to the corresponding value $(2.85 \AA)$ in liquid $\mathrm{H}_{2} \mathrm{O} .{ }^{16}$ So far, some infinite cyclic water chains have been reported, as exemplified by T4(1), T4(1)6(1), T4(2)6(2), T5(2), T6(1) and T6(2) modes, ${ }^{17}$ but their cyclic chains decorated by branch-like $\mathrm{H}_{2} \mathrm{O}$ molecules are very rare. ${ }^{18}$ The $\left[\left(\mathrm{H}_{2} \mathrm{O}\right)_{7}\right]_{n}$ chain in 3 can be regarded as T6(1) chain decorated by one branch-like $\mathrm{H}_{2} \mathrm{O}$ molecule, which exhibits a new type of cyclic water chain. Notably, some metal coordination polymers of $\mathrm{L}^{-}$ ligands have been reported, but no water chains are observed within their extended architectures. ${ }^{5,6}$ Therefore, 3 offers the only example of three-dimensional architecture based on $\mathrm{L}^{-}$ ligands with channels filled by chilopod $\left[\left(\mathrm{H}_{2} \mathrm{O}\right)_{7}\right]_{n}$ chains.

More interestingly, some three-dimensional extended frameworks are built up from the linkages of metal ions and a mixed bridge of $\mathrm{L}^{-}$ligand and aromatic carboxylate to date, ${ }^{5 b-g}$ but similar three-dimensional architectures containing only

Table 1 Crystallographic data for $1-3$

\begin{tabular}{|c|c|c|c|}
\hline & 1 & 2 & 3 \\
\hline Formula & $\mathrm{C}_{20} \mathrm{H}_{18} \mathrm{~N}_{12} \mathrm{NiO}_{2}$ & $\mathrm{C}_{20} \mathrm{H}_{14} \mathrm{CoN}_{12}$ & $\mathrm{C}_{40} \mathrm{H}_{44} \mathrm{Cl}_{2} \mathrm{Co}_{4} \mathrm{~N}_{24} \mathrm{O}_{9}$ \\
\hline Fw & 517.15 & 481.36 & 1311.61 \\
\hline Space group & $P \overline{1}$ & $C 2 / c$ & $C 2 / c$ \\
\hline$a, \AA$ & $7.4760(8)$ & $9.3788(6)$ & $32.117(4)$ \\
\hline$b, \AA$ & $7.9402(7)$ & $12.9170(7)$ & $6.5151(8)$ \\
\hline$\beta, \circ$ & $98.119(4)$ & $95.654(2)$ & $113.333(3)$ \\
\hline$\gamma$, & $106.700(3)$ & 90 & 90 \\
\hline$V, \AA^{3}$ & $505.87(9)$ & $3843.0(4)$ & $4910.6(10)$ \\
\hline$Z$ & 1 & 8 & 4 \\
\hline$T, \mathrm{~K}$ & $289(2)$ & 296(2) & $296(2)$ \\
\hline Calcd density, $\mathrm{mg} \mathrm{m}^{-3}$ & 1.698 & 1.664 & 1.774 \\
\hline No. of param & 168 & 298 & 359 \\
\hline$R_{1}[I>2 \sigma(I)]$ & 0.0581 & 0.0317 & 0.0471 \\
\hline$w R 2$ (all data) & 0.1468 & 0.0779 & 0.1387 \\
\hline GOOF on $F^{2}$ & 1.076 & 1.060 & 1.057 \\
\hline
\end{tabular}


one type of $\mathrm{L}^{-}$ligand are relatively scarce, and the limited examples include $\left[\mathrm{Cu}_{2}\left(\mu_{4}-\mathrm{L}\right)_{2}\right]_{n}$ with 4 -connected $\mathrm{SrAl}_{2}$ topology constructed by simple $\mathrm{Cu}^{+}$ions and $\mu_{4}-\mathrm{L}$ bridges, ${ }^{5 \boldsymbol{h}}$ and $\left[\mathrm{Cu}_{2}{ }^{-}\right.$ $\left.\mathrm{Cl}\left(\mu \mu_{5}-\mathrm{L}\right)\right]_{n}$ with bimodal fsc-3,5-Cmce-2 topology based on the combination of $\mathrm{L}^{-}$ligands and dimeric $\left[\mathrm{Cu}_{2} \mathrm{Cl}\right]^{+}$cluster units, ${ }^{5 i}$ in which the number of metal ions within the cluster unit is not more than two, but the number of $\mathrm{Co}^{2+}$ ions in the $\left[\mathrm{Co}_{4}\left(\mu_{3}-\right.\right.$ $\left.\mathrm{OH})_{2}\left(\mu_{2}-\mathrm{Cl}\right)_{2}\right]^{4+}$ cluster of 3 is four. Hence, 3 is the only example of $3-\mathrm{D}$ framework based on the linkages of high-nuclear magnetic $\left[\mathrm{Co}_{4}\left(\mu_{3}-\mathrm{OH}\right)_{2}\left(\mu_{2}-\mathrm{Cl}\right)_{2}\right]^{4+}$ clusters and $\mathrm{L}^{-}$ligands.

\section{Magnetic properties}

The magnetic susceptibilities of polycrystalline samples of 1-3 were measured on cooling from 300 to $2 \mathrm{~K}$ in an applied field of 1000 Oe. The values of $\chi_{\mathrm{M}} T$ at $300 \mathrm{~K}$ are $1.25 \mathrm{~cm}^{3} \mathrm{~K} \mathrm{~mol}^{-1}$ for 1 and $2.59 \mathrm{~cm}^{3} \mathrm{~K} \mathrm{~mol}^{-1}$ for 2 (Fig. 3), which are higher than the spin-only value for one isolated $\mathrm{Ni}^{2+}$ ion $\left(1.0 \mathrm{~cm}^{3} \mathrm{~K} \mathrm{~mol}^{-1}, S=1\right)$ and $\mathrm{Co}^{2+}$ ion $\left(1.875 \mathrm{~cm}^{3} \mathrm{~K} \mathrm{~mol}^{-1}, S=3 / 2\right)$. This phenomenon in 2 is very common for $\mathrm{Co}^{2+}$ due to the significant orbital contribution, ${ }^{\mathbf{1 9}}$ and it in $\mathbf{1}$ could result from the orbital contribution of the ${ }^{3} \mathrm{~A}_{2 \mathrm{~g}}$ ground state of the high-spin octahedrally coordinated $\mathrm{Ni}^{2+}$ ion. ${ }^{20}$ The values of $\chi_{\mathrm{M}} T$ slowly decrease upon decreasing temperature and the $\chi_{\mathrm{M}} T$ values are $1.21 \mathrm{~cm}^{3} \mathrm{~K}$ $\mathrm{mol}^{-1}$ for 1 (at $20 \mathrm{~K}$ ) and $2.23 \mathrm{~cm}^{3} \mathrm{~K} \mathrm{~mol}^{-1}$ for 2 (at $70 \mathrm{~K}$ ). On further cooling, another sharply decreases of $\chi_{\mathrm{M}} T$ are observed, to $0.52 \mathrm{~cm}^{3} \mathrm{~K} \mathrm{~mol}^{-1}$ for 1 and $1.31 \mathrm{~cm}^{3} \mathrm{~K} \mathrm{~mol}^{-1}$ for 2 at $2 \mathrm{~K}$. The plots are indicative of typical antiferromagnetic interactions between the adjacent $\mathrm{M}^{2+}$ ions $\left(\mathrm{M}=\mathrm{Ni}^{2+}\right.$ and $\left.\mathrm{Co}^{2+}\right)$. In order to assess the possible dynamics of magnetization, ac susceptibility measurements were performed under zero dc field and 2.5 Oe ac field oscillating at different frequency (Fig. S5 $\dagger$ ). However, the results show a complete absence of an out-of-phase component above $2 \mathrm{~K}$.

The value of $\chi_{\mathrm{M}} T$ at $300 \mathrm{~K}$ was $12.20 \mathrm{~cm}^{3} \mathrm{~K} \mathrm{~mol}^{-1}$ for 3 , upon cooling, $\chi_{\mathrm{M}} T$ decreases quickly up to $c a .20 \mathrm{~K}$ before going through minima around $20 \mathrm{~K}$, then rises rapidly to a sharp maximum at $10 \mathrm{~K}$, and finally drops rapidly due to saturation effects (Fig. 4a). The phenomenon is reminiscent of ferromagnetic behavior. Analyses of the $\chi_{\mathrm{M}}{ }^{-1} v s$. T data above $150 \mathrm{~K}$ using the Curie-Weiss law give estimated Curie constants were 14.01 $\mathrm{cm}^{3} \mathrm{~K} \mathrm{~mol}^{-1}$ and Weiss constants $(\theta)$ were $-49.19 \mathrm{~K}$ for 3 . The Curie constants are normal for octahedrally coordinated $\mathrm{Co}^{2+}$ and the negative Weiss constants indicate intracluster antiferromagnetic coupling above $150 \mathrm{~K}$. The negative value of $\theta$ and the initial decrease of $\chi_{M} T$ should be due to the synergistic effect of spin-orbital coupling of $\mathrm{Co}^{2+}$ and the antiferromagnetic coupling through the tetrazolate bridge. The ferrimagnetic behavior has been confirmed by the ZFC-FC magnetization measurements 20 Oe (Fig. 4b). The curve exhibit small differences and both have a sharp maximum at $c a .10 \mathrm{~K}$, suggesting the occurrence of interlayer antiferromagnetic ordering below $T_{\mathrm{N}}=10 \mathrm{~K}$ and a canting angle of about $0.37^{\circ}$. The $\chi_{\mathrm{M}}$ versus $T$ data at different fields (100-5000 Oe) (Fig. S6†) reveal that an abrupt increase of $\chi_{M}$ values below about $10 \mathrm{~K}$ is influenced by increasing the applied field, which becomes insignificant until almost invisible at about 5000 Oe, owing to the saturation effects. For the alternating current (ac) susceptibilities at different frequencies (Fig. 4c), a sharp peak was observed at $c a$. $10 \mathrm{~K}$ in both the real and imaginary components, further confirming the long-range ordering of spin-canted antiferromagnetic in 3 and coinciding with the $T_{\mathrm{N}}$ obtained in ZFC/FC measurements. The spin canting may be caused by the antisymmetric exchange interaction between the $\mathrm{Co}^{2+}$ ions in the chain, as well as the single-ion magnetic anisotropy of $\mathrm{Co}^{2+}$. The isothermal magnetization of 3 was measured at 2-5 $\mathrm{K}$ as a function of applied magnetic field up to $5 \mathrm{~T}$ following cooling in zero field (Fig. S7 $\dagger$ ). The value reaching $3.64 \mathrm{~N} \beta$ is lower to that expected for corresponding theoretical value assuming 12 $\mathrm{N} \beta$ per $\mathrm{Co}_{4}$ unit at $5 \mathrm{~T}$, also confirming the ferrimagnetic behavior. As shown in Fig. 4d, the isothermal magnetization displays an obvious hysteresis loop with a relatively large coercive field and remnant magnetization at $2 \mathrm{~K}$.

\section{Conclusions}

Although a few low-dimensional magnetic metal coordination polymers of bifunctional bridges containing imidazolate and tetrazolate groups have been reported to date, they generally exhibits antiferromagnetic behavior. 3 not only presents the only example of three-dimensional framework based on the linkages of rare $\left[\mathrm{Co}_{4}\left(\mu_{3}-\mathrm{OH}\right)_{2}\left(\mu_{2}-\mathrm{Cl}\right)_{2}\right]^{4+}$ mixed oxo-chloroclusters and bifunctional imidazolate/tetrazolate bridges, but also show unusual spin-canting. Furthermore, the similar bifunctional imidazolate/tetrazolate bridges coordinate to the magnetic metal ions to often form varied metal coordination polymers with octahedrally coordinated metal centers, but 2 is the only example of the magnetic tetrahedral metal coordination polymer with tetrahedrally coordinated metal centers of bifunctional imidazolate/tetrazolate bridges. These results enrich structural types of magnetic metal coordination polymers of bifunctional imidazolate/tetrazolate bridges, and offer possibilities to prepare other novel metal coordination polymers with important magnetic behavior using paramagnetic metal ions in combination with other bifunctional imidazolate/ tetrazolate bridges.

\section{Conflicts of interest}

There are no conflicts to declare.

\section{Acknowledgements}

This work was supported by the NNSF of China (No. 21671029 and 21601038), the NSF of Chongqing (No. cstc2015jcyjBX0117 and cstc2018jcyjAX0157), Program for leading talents of scientific and technological innovation in Chongqing (No. CSTCCXLJRC201707), the innovation Program for Chongqing's overseas Returnees (No. cx2018008), and Program for Excellent Talents in Chongqing Higher Education Institutions. The authors are also grateful to Chongqing Normal University for financial support (No. 14CSLJ02, 13XLZ07). 


\section{Notes and references}

1 (a) S. Hill, R. S. Edwards, N. Aliaga-Alcalde and G. Christou, Science, 2003, 302, 1015-1018; (b) M. N. Leuenberger and D. Loss, Nature, 2001, 410, 789-793; (c) L. Bogani and W. Wernsdorfer, Nat. Mater., 2008, 7, 179-186; (d) E. Saitoh, H. Miyajima, T. Yamaoka and G. Tatara, Nature, 2004, 432, 203-206; (e) M. Yamanouchi, D. Chiba, F. Matsukura and H. Ohno, Nature, 2004, 428, 539-542.

2 (a) J. López-Cabrelles, M. Giménez-Marqués, G. M. Espallargas and E. Coronado, Inorg. Chem., 2015, 54, 10490-10496; (b) T. C. Stamatatos, S. P. Perlepes, C. P. Raptopoulou, A. Terzis, C. S. Patrickios, A. J. Tasiopoulos and A. K. Boudalis, Dalton Trans., 2009, 3354-3362.

3 (a) R. Gautier and R. Clérac, Cryst. Growth Des., 2017, 17, 864-869; (b) M. M. Dîrtu, A. D. Naik, A. Rotaru, L. Spinu, D. Poelman and Y. Garcia, Inorg. Chem., 2016, 55, 4278-4295.

4 (a) F. Yang, B. Li, W. Xu, G. Li, Q. Zhou, J. Hua, Z. Shi and S. Feng, Inorg. Chem., 2012, 51, 6813-6820; (b) E. Yang, Z. Liu, T. Liu, L. Li and X. Zhao, Dalton Trans., 2011, 40, 8132-8813.

5 (a) Z. Shi, J. Peng, X. Yu, Z. Zhang, X. Wang and W. Zhou, Inorg. Chem. Commun., 2014, 41, 8-87; (b) J. Sun, D. Zhang, L. Wang, R. Zhang, J. Wang, Y. Zeng, J. Zhan, J. Xu and Y. Fan, J. Solid State Chem., 2013, 206, 286-292; (c) S. Hou, J. Tan, Z. Lian, D. Zeng, T. Huang, B. Huang, S. Zheng, J. Fan and W. Zhang, Inorg. Chem. Commun., 2014, 47, 112118; (d) Z. Shi, J. Peng, Z. Zhang, X. Yu, K. Alimaje and X. Wang, Inorg. Chem. Commun., 2013, 33, 105-108; (e) S. Zheng, L. Zhang, J. He, J. Fan and W. Zhang, Inorg. Chem. Commun., 2016, 66, 19-23; (f) Y. Xie, J. He, T. Wang and H. Zeng, J. Coord. Chem., 2015, 68, 1733-1742; $(g)$ X. Hu, C. Qin, L. Zhao, F. Liu, K. Shao and Z. Su, RSC Adv., 2015, 5, 49606-49613; (h) D. Ma, L. Qin, K. Lu, H. Guo and J. Liu, Inorg. Chem. Commun., 2012, 24, 87-90; (i) Q. Tang, J. Zhou, F. A. Almeida Paz, L. Fu, H. Xiao, Q. Zhou and J. Li, Dalton Trans., 2017, 46, 1372-1376; (j) L. Wang, W. Yang, W. Zhu, X. Guan, Z. Xie and Z. Sun, Inorg. Chem., 2014, 53, 11584-11588; ( $k$ ) J. Chen, Q. Zhang, Z. Liu, S. Wang, Y. Xiao, R. Li, J. Xu, Y. Zhao, F. Zheng and G. Guo, Dalton Trans., 2015, 44, 10089-10096.

6 (a) X. Li, Y. Chen, X. Chi, Y. Xu, Q. Yang, H. Zhang, J. Zhang and D. Xiao, Inorg. Chim. Acta, 2015, 437, 159-166; (b) $\mathrm{H}$. Kuai, X. Cheng and X. Zhu, Inorg. Chem. Commun., 2012, 25, 43-47.
7 (a) J. M. Zadrozny and J. R. Long, J. Am. Chem. Soc., 2011, 133, 20732-20734; (b) F. Yang, Q. Zhou, Y. Zhang, G. Zeng, G. Li, Z. Shi, B. Wang and S. Feng, Chem. Commun., 2013, 49, 52895291; (c) J. Palion-Gazda, B. Machura, R. Kruszynski, T. Grancha, N. Moliner, F. Lloret and M. Julve, Inorg. Chem., 2017, 56, 6281-6296.

8 (a) S. Hu, L. Yun, Y. Zheng, Y. Lan, A. K. Powell and M. Tong, Dalton Trans., 2009, 1897-1900; (b) X. Li, G. Zhuang, X. Wang, K. Wang and E. Gao, Chem. Commun., 2013, 49, 1814-1816.

9 (a) Y. Chen, Y. Song, Y. Zhang and J. Lang, Inorg. Chem. Commun., 2008, 11, 572-575; (b) K. Darling, W. Ouellette, A. Prosvirin, S. Freund, K. R. Dunbar and J. Zubieta, Cryst. Growth Des., 2012, 12, 2662-2672; (c) M. Li, G. Yang, S. Li, H. Zang, G. Xu, K. Shao and Z. Su, Inorg. Chem. Commun., 2010, 13, 1203-1206.

10 (a) W. Ouellette and K. Darling, Dalton Trans., 2011, 40, 12288-12300; (b) E. Yang, Z. Liu, X. Wu, H. Chang, E. Wang and X. Zhao, Dalton Trans., 2011, 40, 10082-10089.

11 K. Xiong, F. Jiang, Y. Gai, Z. He, D. Yuan, L. Chen, K. Su and M. Hong, Cryst. Growth Des., 2012, 12, 3335-3341.

12 G. M. Sheldrick, Shelxs-97, Program for the Solution of Crystal Structures, University of Göttingen, Göttingen (Germany) 1997.

13 G. M. Sheldrick, Shelxl-97, Program for the Refinement of Crystal Structures, University of Göttingen, Göttingen (Germany) 1997.

14 S. Karmakar and S. Khanra, CrystEngComm, 2014, 16, 23712383.

15 P. Grosshans, A. Jouaiti, M. W. Hosseini and N. Kyritsakas, New J. Chem., 2003, 27, 793-797.

16 A. H. Narten, W. E. Thiessen and L. Blum, Science, 1982, 217, 1033-1034.

17 (a) L. Infantes, J. Chisholm and S. Motherwell, CrystEngComm, 2003, 5, 480-486; (b) S. M. Hammer, R. Panisch, M. Kobus, J. Glinnemann and M. U. Schmidt, CrystEngComm, 2009, 11, 1291-1302; (c) L. Infantes and S. Motherwell, CrystEngComm, 2002, 4, 454-461.

18 S. R. Choudhury, A. D. Jana, E. Colacio, H. M. Lee, G. Mostafa and S. Mukhopadhyay, Cryst. Growth Des., 2007, 7, 212-214.

19 (a) D. Cao, J. Feng, M. Ren, Y. Gu, Y. Song and M. D. Ward, Chem. Commun., 2013, 49, 8863-8865; (b) M. Murrie, Chem. Soc. Rev., 2010, 39, 1986-1995.

20 (a) O. Oms, A. Dolbecq and P. Mialane, Chem. Soc. Rev., 2012, 41, 7497-7536; (b) Y.-J. Sun, Q.-Q. Huang, T. Tano and S. Itoh, Inorg. Chem., 2013, 52, 10936-10948. 